\title{
Individualization in the widening participation debate
}

\author{
Sally Baker*a , B. Brown ${ }^{\mathrm{b}}$ and J. A. Fazey ${ }^{\mathrm{a}}$ \\ ${ }^{\mathrm{a}}$ University of Wales, UK; ${ }^{\mathrm{b}}$ De Montfort University, UK
}

\begin{abstract}
We provide an analysis of some recent widening participation literature concerning the barriers preventing non-traditional students accessing higher education. This literature criticizes higher education institutions and staff, opening up the academics' attitudes and skills to inquiry. We follow the genesis of four themes in the literature and these are visited in turn to provide substantive arguments. Students' accounts of their experiences are taken as if they were a systematic analysis of higher education institutions and result in an individualistic analysis of the problems related to access and progression. Beck described such assumptions and devices as individualization. We question the use of such pervasive individualism in the widening participation debate.
\end{abstract}

\section{Introduction}

For nearly a decade, the UK's New Labour Government has pursued a policy of widening participation in higher education, to engage more diverse social and cultural groups (DfEE, 2000), with a target of 50\% participation amongst the 18-30 age group by 2010. It was envisaged that this policy would involve significant shifts amongst the population of applicants. However, the recent report from HEFCE (2005), analysing the results of the widening participation policy among young people, made sombre reading for its advocates. It reveals that higher education is still dominated by students from wealthier socio-economic groups. The difference in participation rates between students from 'advantaged' neighbourhoods and 'disadvantaged' neighbourhoods actually increased during 1994-2000. Despite these stubborn inequalities, widening participation has had a considerable effect on the higher education system. There are now many more people entering higher education, and thus greater numbers of people from groups previously not usually entering higher education. This fundamental demographic shift is bringing with it a unique set of

\footnotetext{
* Corresponding author. Research Institute for Enhancing Learning, School of Education, University of Wales, Normal Site, Holyhead Road, Bangor, Gwynedd LL57 2 PX, UK. Email: edpd60@bangor.ac.uk
} 
difficulties as hitherto separate ideas, values and styles of life are brought together. Changes are being wrought not only in the applicants, but are being urged with increasing vigour upon higher education institutions.

What interests us are the conceptual shifts that accompany these demographic and policy changes. There are reconfigurations of what it means to be a student and what higher education entails, as well as attempts to reformulate the very nature of higher education institutions themselves. These partly involve changes in the realm of public discourse, but more interestingly, some reconfigurations are changing the conceptual landscape of thinking about education with little debate or effective challenge.

The term 'non-traditional' is generally applied to applicants who are over 21years-old, or from ethnic minorities and/or socio-economic groups who traditionally have been under-represented in higher education, or students with qualifications other than A levels. Such students make up an increasing proportion of the higher education intake, particularly in the 'new universities' (Connor et al., 1999). Under the 'top-up fees' policy, higher education institutions are obliged to demonstrate to the new access regulator, the Office of Fair Access, that they are widening access and providing support for poorer students (DfES, 2003a, b; Jary \& Jones, 2003). There is concern that 'non-traditional' students have a much higher dropout rate than traditional students (HEFCE, 1999).

There is a growing body of literature which has attempted to characterize the difficulties experienced by non-traditional students in higher education. This literature shows some interesting tendencies. To a substantial extent, it may be perceived as falling into two 'camps'. One of these camps comprises literature that is often published by educational sociologists and draws extensively on sociological theory for an exploration of the difficulties encountered by non-traditional students. The other camp, while dealing with the same group of students and their problems, often makes no, or little, reference to sociological theory and relies on an analysis that problematizes the higher education system itself. We are struck by the scant interaction between the two camps. Although there are a small number of scholars who are 'bridging the divide', the chasm is obvious. We have classified the two types of literature as 'sociological literature' and 'empowerment literature'. We have adopted the term 'empowerment literature' because the stated aim of many of these researchers is to empower students. For example, one prolific author, Marion Bowl, goes as far as to maintain that her approach involves 'taking sides' (Bowl, 2000, p. 33), i.e., she takes the side of the students. In this paper, we attempt to analyse the kinds of explanations offered in this empowerment literature as to why non-traditional students so often have problems engaging with higher education. It is in this micropolitics of education, where the attitudes, dispositions and cognitive capacities of the participants are brought into focus, that some interesting conceptual shifts are observable.

We were interested in the way that implicit models of the process of being educated have been developed by researchers inquiring into the higher education process. Consequently, we will attend to the way in which notions of 'limitations' and 'barriers' are constructed in situ as areas of scrutiny. The way in which the 
nature of potential applicants and staff in higher education are conceptualized and problems are formulated in higher education has an important relationship with policy and politics.

The empowerment literature frequently adopts an approach where it is the students and their experiences that are taken as the point of reference and it is higher education institutions that are the objects of critical scrutiny. This ascendant strand in the empowerment literature in the early twenty-first century has emphasized an empowering rhetoric, in which students 'speak for themselves' (Archer \& Hutchings, 2000; Bamber \& Tett, 2001; Bowl, 2001, 2003; Hutchings \& Archer, 2001; Leathwood \& O'Connell, 2003). This style, using extensive quotes from the students, is pervasive in this debate and helps to create a sense of freshness, realism and immediacy. This sets the stage for a further manoeuvre on the part of some authors, where a shift is undertaken from the students' grievances to an analysis of the higher education institutions' role in maintaining inequalities. This might at first seem refreshing and it might present some new tools for challenging inequalities and maximizing the capacity of individuals. It could also be used to shape the knowledge, contest those authorities and configure those practices that govern students while maintaining that they are improving them personally and increasing their employability (Rose, 1996). However, in the empowerment literature, it is rare to see the governmental powers of education exposed or challenged. Students' complaints have been taken as if they were veridical analyses of higher education institutions. This is a denatured variant of 'empowerment' since the term was originally discussed by Friere (1972), who noted that the empowered are not the same as the powerful and we suggest that empowerment in this context has lost the original socio-political analytical power.

In this paper, we explore four themes found within the literature reviewed. We visit each theme in turn, although there are some overlapping and interlinked concepts and themes.

\section{Review methods}

A literature search was carried out on work since 1999, the start of the period when work on the barriers facing non-traditional students accessing higher education began to proliferate. Papers were selected that related to widening participation and access of non-traditional students to higher education. The terms 'non-traditional student', 'widening participation' and 'widening access' were entered into the ERIC (BIDS) database, the British Educational Index and Educational Research Abstracts. There is a considerable amount of 'grey literature' in this area such as Government policy documents and circulars and reports from bodies such as the Committee of Vice-Chancellors and Principals (CVCP) and the Higher Education Funding Council for England (HEFCE). This was not formally included in the review as such documents tend actually not to contain research in the area but more usually are statements of intent, policy or opinion.

The papers were subjected to a close reading by the authors with a view to identifying themes relating to the restrictions on access and barriers faced by students. 
The coding process began with an initial intuition that there were important issues at stake in the way the tension between students and higher education institutions was conceptualized. Texts of articles were inspected and searched electronically for occasions where issues relating to barriers to access or tension between students and institutions were mentioned. Agreement was reached on the features which provided evidence of authors trying to make sense of these difficulties and offer an explanation for them, either explicitly or implicitly.

The presentation of results here follows a series of themes, which, in line with a grounded theory approach (Glaser \& Strauss, 1967; Strauss \& Corbin, 1998), first emerged as 'open codes', taking the form of intuitive guesses used to 'crack the data open'. They were subsequently developed and elaborated so as to resemble Strauss and Corbin's notion of 'axial codes'. At the core of this analysis, the code to which the themes are related concerns the notion of elitism and unhelpfulness on the part of higher education staff. This leads to the notion of incompatibility between nontraditional students and higher education institutions, and the idea that higher education staff have 'failed to adapt'.

\section{Analytic commentary}

The presentation of findings from the empowerment literature review is organized in terms of four major themes, namely:

1. The literature associated with higher education institutions and the essence of academia.

2. The elitist and unhelpful qualities that the empowerment literature attributes to higher education staff.

3. The higher education institutions and all that is associated with them-a kind of Brideshead Revisited image.

4. The image of higher education institutions and their students as variously 'sad', miserable or idle.

These themes are sustained dynamically by the authors of the empowerment literature from the basic raw material of participants' accounts. Let us first explore the implicit models of the literature associated with higher education and the essence of academia.

\section{The literature associated with higher education institutions and the essence of academia}

Pickerden (2002) talks about university literature constituting a barrier: 'university application forms and recruitment literature can be a barrier, as they are written in a complex manner requiring considerable prior knowledge' (p. 41). 'It was not enough to simply take a prospectus and a course leaflet. There are barriers to widening participation in the language and descriptions used' (p.42).

Some of the fiercest criticisms of higher education institutions in the empowerment literature centre on the very nature of academia itself. Some students struggled 
with the academic demands made upon them in higher education. Bowl (2001) states that: 'the difficulties experienced by ... students included ... reading and structuring assignments' (p. 156). Bamber and Tett (2001) are extensively critical of academic expectations:

The students report that engaging with literature, having to produce formal essays and comply with all the other aspects of academic literacies, often seems like unnecessary hoop-jumping. Some retain a distrust of academic language and struggle to master it throughout the length of the course. (Bamber \& Tett, 2001, p. 12)

Bamber and Tett also suggest that 'texts that are inaccessible to all but the most academically able could set back, rather than enhance, intellectual development' (p. 14). This extensive critique of the day to day expectations of academia suggest that the authors of such literature are expecting higher education to fulfil a role radically different from that which has traditionally been expected from it. It is as if these requirements, rather than being part of a particular scholarly tradition, are imposed capriciously and awkwardly by the staff themselves. The picture here is of an individualized practice where academic languages and conventions are imposed with cruelty on unwilling students.

\section{Higher education staff: elitist and unhelpful?}

Bowl (2000, 2001, 2003), paints a particularly negative picture of higher education institutions and their staff. In the words of one of her interviewees:

I don't think they're helpful at all really. ... There's no backup, no support. ... And when I talked to my tutor about my grant thing, he said: 'oh well you'd better get that cleared up, because [the higher education institution] don't hang about waiting for people to pay their tuition fees. They're going to come after you'. (Bowl, 2000, p. 34)

Bowl observes that 'relations between student and tutor can be problematic' (Bowl, 2001, p. 157). She also states that 'feelings of marginalization are affected by support and by the attitudes of tutors' (Bowl, 2000, p. 34).

Another of Bowl's interviewees felt that: 'sometimes the lecturers haven't got time for you. They hand out the work; you can feel isolated when you come home because you've got bills to pay' (Bowl, 2000, p. 36).

Bowl explicitly identifies herself as working within a 'social justice framework' (Bowl, 2000, p. 33), foregrounding students' grievances. This lends itself to an implied socio-structural analysis of higher education institutions. Rather than being a consequence of their thinking or demographic position, students' accounts are presented as fully formed and veridical. There is no critical leverage on how the students' reported experiences are constructed and they are presented as if they were a socio-structural analysis of the shortcomings of the institutions. What is effectively sidelined in Bowl's work is any account of how the students' experiences relate to broader contextual factors, such as larger scale inequalities of politics, economics and social issues. Although these are considered tangentially in some of the other widening participation literature, the approach taken by Bowl is 
relentlessly individualistic. Within this context staff are somehow morally defective and bear the weight of responsibility for changing the institution. The interpretation or gloss of the comments is unrelentingly negative towards the higher education institution. The tutor who was perceived as being unhelpful because of his comments over tuition fees might even, in using these words, be commiserating with a student over a draconian regime. In any case, a passing knowledge of life in higher education would suggest he would not be empowered to do anything to assist the student in the way she expected. He would be unlikely to have control over the workings of the institution or over Government higher education policy. Another student thought that 'raising issues' with staff might endanger her chances of completing the course (Bowl, 2000, p. 36). This consolidates a view of higher education staff as vengeful and who have yet again failed to adapt to the new circumstances confronting them. Whether or not this fear might be grounded in reality is not our major concern. What is at stake is the sense in which it is taken to be true in this particular strand of argument.

This process of identifying staff themselves as being responsible resonates with larger scale process of individualization in contemporary societies. The contemporary individual has the responsibility of choosing and changing their social identity as well as taking the risks in doing so (Beck, 1992, p. 88). Thus, individual staff are rendered responsible for the regime in which they are embedded and made responsible for the difficulty of adapting their institution to the needs of their new found constituency of customer-students.

In line with the notion of individualization, Bamber and Tett (2001) also suggest that higher education staff need to change and that 'a two-way process of change and development is required' but insist that lecturers might have to 'critically examine and change their own attitudes and practices' (p. 8). Bamber and Tett believe that critical thinking and re-examining experience can be an emotionally challenging and threatening process, 'hence the need for a supportive course environment, especially in terms of the relationship with tutors'. They also maintain that 'staff working in [an elite] institution who aim to enhance social equity because of a concern for social justice find that they are marginalized within their institutions' (Bamber \& Tett, 2001, p. 15).

Smith (2000) talks of 'suggestions of elitist attitudes' and notes that some feel that higher education academic staff are 'more concerned with research than with the needs or interests of a group in the community' (p. 28). MacDonald and Stratta (2001) investigated whether non-traditional students were seen by tutors as a 'problem'. Initially, they found that there was an unwillingness to see non-traditional students as a distinct group - tutors' quotes stressed that they wanted to treat them as students 'on their own merits' (p. 251). In further interviews with tutors, characteristics of non-traditional students did arise-these characteristics were positive. Among tutors' observations were: 'non-standard entrants will contribute more readily' and that 'as a group they tend to be slightly more articulate and more assertive' (p. 251). Tutors did talk of the 'anxiety' of performance that non-traditional students often displayed (MacDonald \& Stratta, 2001, p. 252). MacDonald and 
Stratta considered that the tutors they interviewed believed that the students' learning was the students' own business and that opening up access to higher education was about allowing students to fit into the situation, not requiring any radical change on the part of the tutors or the institution. Thus despite the individually supportive comments made by staff, MacDonald and Stratta considered that staff were actually undermining non-tradition students as a group by articulating such views. Where explanation involving social structures or collective concerns were used, these explanations again resulted in negative portrayals of staff in higher education.

The pervasive picture painted of higher education staff in much of the empowerment literature is of, at worst, elitist, hostile individuals, or at best, indifferent people who are unconcerned about the difficulties non-traditional students face. This picture of university staff suggests that their focus is on elite concerns and also emerges from literature on pre-higher education preparatory courses as part of the 'Aim Higher' initiative (Slack, 2003). A similar image is built up by Leathwood and O' Connell (2003) in their coverage of the attitude of some staff in elite institutions who talk disparagingly of 'Mickey Mouse' institutions and degrees suitable for less able students. It seems that to construct a model of hostile higher education staff, arguments have been built on a variety of sources of information distributed across a number of different sites and structures-students' intuitions, introductory programmes, press reports and the like-rather than the actual higher education staff working with such students, who on the whole were rather positive. Some of these arguments are constructed by important points being supported by affording a highly particular means of privilege to certain kinds of evidence over others. The accounts from staff seem to be placed lower in the hierarchy of credibility than those of the students.

In this way, a number of authors of empowerment literature have developed their arguments so as to depend on the veracity of student participants' comments. This represents a solipsistic retreat into a state of analysis where things are the case because people say they are. At the same time, it is clear that many of those contributing to the empowerment literature have not undertaken a systematic sociologically informed analysis of the nature of institutions or society or the material obstacles to change, but have instead relied on the subjective, individualized realm of student experiences. This enables the authors to take what the students say as itself the analysis of the higher education system. Broader structural inequalities have been collapsed into notions of financial difficulty and poverty. Some authors have been quite explicit in their condemnation of the higher education institutions themselves and their staff, constructing them as elitist and indifferent to the problems facing non-traditional students. In the view of such authors in the widening access arena, it is this individualized, personal barrier that prevents non-traditional students accessing higher education or progressing once they have arrived, rather than, for example, social-structural factors beyond the academy. A similar process can be seen when we look at the empowerment literature dealing with other barriers that non-traditional students face. 


\section{The higher education institutions and all that is associated with them}

There is much emphasis in the empowerment literature on the need for institutions and the life and essence of higher education to change. Some authors simply allude to a social milieu very different from that familiar to non-traditional students and suggest that this causes serious problems for them. George and Gillon (2001) talk of 'an alienating, not merely an alien, world' (p. 16). Bowl (2001, p. 145): 'some talked of the alienation they felt from the ethos of higher education institutions, and a sense of isolation, that they felt other students did not share'. There are also more specific problems identified, for example, financial problems faced by non-traditional students, childcare issues, academic problems, the language used in higher education documents, the higher education environment, cultural issues, time-management problems and the image of higher education institutions and their students. Financial issues crop up again and again in the widening participation literature. Sometimes, they are presented as being caused by the higher education institutions:

Administrative regulations discourage payment by instalments, and insist upon payment by cheque or standing order, failing to recognize that many students from lowincome groups do not operate a bank account and are unwilling to apply for student loans (the prerequisite for one type of fee waiver). (Pickerden, 2002, p. 40)

'Barriers within the higher education system may include the cost of participation, including direct costs and living costs' (Thomas, 2001, p. 365). Bowl (2001) observed 'the word-processing of essays was a course requirement of which she [the student] had not been made aware ... she ... could not afford a computer' (p. 147). Bowl (2000) talks of the 'insensitivity' of higher education institutions to the students' financial problems:

... examples of such insensitivity were highlighted in the large booklists given to students, regardless of the costs of books and without guidance as to the need to buy them and in the common assumption that students would have access to personal computers. (Bowl, 2000, p.35)

Since the abolition of maintenance grants, student poverty has been well-documented, yet much of the empowerment literature implies that the higher education institutions themselves are responsible for this and it is their job to remedy the situation. The personal feelings of the students, the client-customer ethos and the apparent indifference of the institution are placed in the foreground of the analysis rather than any focus on larger scale variables. The major locus of explanation and analysis for this literature is in the experience of the students.

These issues are of course legitimate topics of enquiry in their own right. However, the manoeuvre that is accomplished in this kind of account is to move directly from the personal accounts of difficulties to the implication that higher education staff are culpable. It is 'dismaying that the tutors do not appear to have taken any action to construct a more inclusive and less oppressive space for all members of the group' (Leathwood \& O'Connell, 2003, p. 609). The implication is that if only the staff would undergo a process of reorientation, then non-traditional students would find participation easier. These assumptions perhaps rely on 
'commonsense' reasoning. If staff were willing to be more 'flexible' (Johnson \& Deem, 2003), or were capable of 'getting out' to meet potential students (Osbourne, 2003) then the situation might be ameliorated. The cultural condition of individualization has helped to identify the individual higher education lecturer as a site for scrutiny and reform.

The empowerment literature also considers other factors that may constitute barriers to non-traditional students. For example, time management crops up, with some non-traditional students finding that they don't have time to read around the subject or to throw themselves wholeheartedly into their course. George and Gillon (2001) state that the 'practicalities of education - time management ... are beyond their means' (p. 16). Bowl (2001) noticed that students were 'reading only what was essential to pass the assignment and snatching time to study wherever they could' (p. 156).

Cultural differences between non-traditional students and higher education institutions are extensively documented. One student interviewed by Bowl (2001) observed: 'If you're not white and middle class, you're not accepted. There's nothing overt, you just sense it' (p. 146).

Bowl (2001) also talks of students finding difficulty with 'comprehending the mysteries of academic culture and conventions' (p. 157) and states that 'dislocation seems to centre on class, gender, and ethnic difference between the overall ethos of the institution and that of the non-traditional student' (p. 157). Thomas (2001) suggests that 'an institutional culture that does not accept, nor accommodate, diversity' (p. 365) is a barrier created by the education system. Hutchings and Archer (2001) state that 'people from lower socio-economic groups perceive higher education to be a culture dominated by the middle-classes and may therefore expect to be alienated' (p. 71).

Race is presented as a problem in the empowerment literature. Archer and Hutchings (2000) found respondents talking about higher education institutions as predominantly white places: 'And like when you see it up there like actually the prospectus it's like White people, White people' (p. 563). There was also a feeling that respondents associated the 'best' higher education institutions with whiteness and middle-classness and perceived higher education institutions with large proportions of black and working class students as not 'good' higher education institutions.

Higher education institutions are held responsible for the demographic mix of students they recruit. This may seem reasonable-it is easy to imagine how marketing departments and admissions tutors determine these polices. However, without wishing to deny the experience of disenfranchised groups in the education system, it is important to be aware of the argumentative strategy that is being pursued here. The students' perceptions, within the studies mentioned above, are granted the status of literally true and substantive analyses of the higher education institutions. The accounts are not grounded or analysed within a social formation, but are presented as literally and unproblematically true. Higher education institutions may be exclusive and unwelcoming places, especially for some disadvantaged 
groups. Our point is that the elision from these experiences to a theory of how higher education institutions work is altogether too rapid to be useful in grasping the systematically structured inequalities in society that make it unlikely that certain groups of students will apply to elite institutions, even before they touch an application form.

\section{Higher education institutions and their students}

Cultural differences were also very clearly illustrated in the fourth theme in the literature. This concerns negative views of higher education institutions and their members held by young people who were not participating in higher education. Such interviewees quoted in Hutchings and Archer (2001) were asked about their images of higher education institutions and higher education students. Some highly negative images were elicited. When asked what sort of picture he had of universities, one respondent replied: 'Shit! Depression! Depression and like the pressure ...' (p. 80). Another: 'Thoroughly boring! ... like a lot of work ... and not much enjoyment' (p. 80). Another still: ' $\ldots$ professor like in a lecture for about four hours chatting complete crap' (p. 80).

A minority discourse found among respondents was that higher education is peopled by middle class students who drink, take drugs, go to parties and are unable to face the real world. Higher education students were variously described as 'snobs', 'trendies', 'hippified people who smoke pot in the toilets and just get stoned every night and drink', 'people who were afraid to hit the big wide world', 'some of them are just there to get a social life, they're the sad ones' (Hutchings \& Archer, 2000, pp. 84-85).

In the face of such devastating images and stereotypes, higher education institutions will already be facing an uphill struggle to recruit students from groups holding these views. Yet at the same time these seem to be presented as barriers that the institutions themselves and their staff are expected to tackle. It is possible that a range of extraneous factors in the broader culture might be involved in creating the image of higher education institutions. Yet it has been suggested that such a negative image is potentially resolvable if only the outreach programmes were appropriately designed (Slack, 2003), or the qualifications offered were made acceptable as 'valid cultural passports' (Warmington, 2003). All of this outlines a growing and increasingly diverse set of roles at which higher education staff are exhorted to succeed and often it is difficult to see what higher education personnel could do to tackle some of these larger scale factors by themselves, yet their inability to do so is seen as a 'failure to adapt'.

\section{Conclusion}

The newly proliferating research on widening participation often identifies higher education staff as responsible for making changes to themselves and their host institutions to enhance the experience of non-traditional students. UK higher education 
staff historically have enjoyed relative autonomy from Government and have hitherto been able to insulate themselves from student grievances. However, the present day alignment of wider-access policies with financial incentives and a new thrust of scholarship makes the present situation different from any faced in the past.

We have attempted to analyse the stance of the empowerment literature where it concerns non-traditional students and their experiences of higher education. The focus of this literature is almost exclusively on the arbitrariness and injustice the students see as inherent in the experience of higher education and the complaints that students have about higher education institutions. This results in a representation of the situation which is narrowly focused on the immediate desires of the students. The individual personalities of higher education staff are also often referred to in this literature and seen as obstacles to a more populist and welcoming university system. By taking a highly individualistic approach, the empowerment literature occludes the manifold ways in which higher education is problematic to non-traditional students and makes a more socio-structural or political approach to the issue difficult to conceptualize. This literature creates an individualized and depoliticized vision of why higher education is not working for these students (Lankshear, 1999).

The picture built up in this literature is a profoundly negative one, with non-traditional students encountering a plethora of barriers and inequalities. That the road of individuals seeking to transcend multiple oppressions and deprivations is a difficult one is certainly not in dispute. What is interesting is that these barriers are presented as if they were put in place by staff of higher education institutions themselves. For example, rather than asking why literacy skills and aspirations are confined to certain sections of the population, some authors would rather criticize university courses for needing them. It is as if a tribe of crusty, hidebound academics are conspiring to keep non-traditional students out of higher education. It may be possible to find members of staff who fit this stereotype, but the empowerment literature opens up to scrutiny the putative attitudes, prejudices and re-skilling needs of this body of people, as objects of inquiry and possible reform, whilst remaining silent about broader patterns of inequality in cultural capital.

Although the literature on widening participation offers occasional accounts of the structural inequalities that hinder non-traditional students, even these inequalities and barriers are often discussed as if they are somehow put in place wilfully by higher education institutions. There is an expectation that it is the responsibility of higher education institutions and their individual employees to remove them.

With individualization, higher education staff have become the agents of their subsistence within the educational market. Business culture has already hegemonized notions of students as customers (Johnson \& Deem, 2003). Literature which stresses the empowerment of students or applicants may present 'solutions' which would be extremely difficult for higher education staff to accomplish, and undertheorizes the constraints faced by higher education institutions, from societal factors and Government policies. For example, the state substantially controls fee levels and 
thus exerts considerable influence over a higher education institution's income and the monies demanded from students.

When barriers which may be more fully explained by reference to broader structures and processes are encountered, these are still conceptualized and explained in individualistic terms. This individualism brings with it the implication that the higher education institutions ought to be doing something about these factors. In Rose's (1990) terms, the 'soul' of the academic is to be brought under the gaze of the confessional and hence may be more readily governed. The picture that emerges is of a system where the staff themselves are the villains of the piece. If this picture gains credence in policymaking circles, the future of higher education staff will not be a happy one. The sociological and economic amnesia of much of the empowerment literature may ultimately do a disservice to universities and non-traditional students by underestimating the nature of the obstacles faced in rising from a less advantaged background to achieve a degree. These obstacles may well not be removed merely by incessant scrutiny of the academics' presumed attitudes and prejudices.

The literature on widening participation is not monolithic-there are, for example, hints that widening participation can be accomplished successfully without demonizing higher education institutions and their staff. Some literature contains other models of non-traditional students and their experience in education which reflect a greater degree of success (Pickerden, 2002). The thrust of this latter literature is that if appropriate support and learning opportunities are put in place to facilitate the progress of non-traditional students, then at least equal benefit should be experienced by traditional students - all will benefit. However, it does attempt to reconstruct the 'soul' of the educator just as stridently, with the added imperative that it benefits the full range of students.

We make a plea for more of the authors of the empowerment literature to adopt a more sociologically nuanced approach to understanding the situation of non-traditional students, so as adequately to conceptualize the other factors that may be at work. For example, some researchers are now interested in issues related to the identity and culture of such groups, but this is a recent phenomenon still somewhat neglected by many in the widening participation arena. Our plea then, involves trying to open up this tendency to individualize issues to scrutiny and see this as an effect of a more pervasive cultural process.

It is only by tackling this in a broad-based fashion that researchers may ultimately aid non-traditional students in their attempts to access higher education. Whilst respecting and validating experiences of exclusion, it should be acknowledged that these are starting points of social analysis rather than completed analyses in their own right.

\section{Notes on contributors}

Sally Baker is a visiting researcher at the University of Wales, Bangor, with an interest in higher education policy and mental health policy as conceptualized by New Labour. 
B. Brown is Reader at De Montfort University, with an interest in healthcare and education communication.

John A. Fazey is Director of the Research Institute for Enhancing Learning, University of Wales, Bangor, and has an interest in enhancing learning performance.

\section{References}

Archer, L. \& Hutchings, M. (2000) Bettering yourself? Discourses of risk, cost and benefit in ethnically diverse, young, working-class non-participants' constructions of higher education, British fournal of Sociology of Education, 21(4), 555-574.

Bamber, J. \& Tett, L. (2001) Ensuring integrative learning experiences for non-traditional students in higher education, Widening Participation and Lifelong Learning, 3(1), 8-16.

Beck, U. (1992) Risk society. Towards a new modernity (London, Sage).

Bowl, M. (2000) Listening to the voices of non-traditional students, Widening Participation and Lifelong Learning, 2(1), 32-40.

Bowl, M. (2001) Experiencing the barriers: non-traditional students entering higher education, Research Papers in Education, 16(2), 141-160.

Bowl, M. (2003) Non-traditional entrants to higher education: 'they talk about people like me (Stokeon-Trent, Trentham Books).

Connor, H., Burton, R., Pearson, R., Pollard, E. \& Regan, J. (1999) Making the right choice: how students choose universities and colleges (London, IES).

DfEE (2000) The excellence challenge. the Government's proposals for widening the participation of young people in HE (London, HMSO).

DFES (2003a) The future of higher education (London, HMSO).

DFES, (2003b) Widening participation in higher education (London, HMSO).

Fairclough, N. (2003) Analysing discourse: textual analysis for social research (London, Routledge).

Friere, P. (1972) Pedagogy of the oppressed (New York, Penguin Books).

George, J. W. \& Gillon, E. J. (2001) What evidence do we need? A case study of widening participation, Widening Participation and Lifelong Learning, 3(3), 15-20.

Glaser, B. G. \& Strauss, A. (1967) The discovery of grounded theory (New York, Aldine).

HEFCE (1999) Performance indicators in higher education. Guide 99/66 (Bristol, HEFCE).

HEFCE (2005) Young participation in higher education (Bristol, HEFCE).

Hutchings, M. \& Archer, L. (2001) Higher than Einstein: constructions of going to university among working-class non-participants, Research Papers in Education, 16(1), 69-91.

Jary, D. \& Jones, R. (2003) Schwartz and all. The 'fair admissions' debate in England-a comment on the English admissions to higher education review, Widening Participation and Lifelong Learning, 5(3), 3-6.

Johnson, R. N. \& Deem, R. (2003) Talking of students: tensions and contradictions for the manager-academic and the university in contemporary higher education, Higher Education, 46, 289-314.

Lankshear, C. (1999) Literacy studies in education: disciplined developments in a post-disciplinary age, in: M. Peters (Ed.) After the disciplines (Westport, CN, Greenwood Press).

Leathwood, C. \& O'Connell, P. (2003) It's a struggle. The construction of the new student in higher education, Fournal of Education Policy, 18(6), 597-615.

MacDonald, C. \& Stratta, E. (2001) From access to widening participation: responses to the changing population in higher education in the UK, Fournal of Further and Higher Education, 25(2), 249-258.

Osbourne, M. (2003) Increasing or widening participation in higher education? A European overview, European Fournal of Education, 38(1), 5-24.

Pickerden, A. (2002) Muslim women in higher education: new sites of lifelong learning, International fournal of Lifelong Education, 21(1), 37-43. 
Rose, N. (1990) Governing the soul: the shaping of the private self (London, Routledge).

Rose, N. (1996) Inventing our selves: psychology, power and personhood (New York, Cambridge University Press).

Slack, K. (2003) Whose aspirations are they anyway?, International fournal of Inclusive Education, $7(4), 325-335$.

Smith, J. (2000) Reaching out to the region. What works? Evaluating higher education strategies for widening participation in the context of a national policy initiative, Widening Participation and Lifelong Learning, 2(3), 23-31.

Strauss, A. L. \& Corbin, J. (1998) Basics of qualitative research: techniques and procedures for developing grounded theory (Thousand Oaks, CA, Sage Publications).

Thomas, L. (2001) Power, assumptions and prescriptions: a critique of widening participation policy-making, Higher Education Policy, 14, 361-376.

Warmington, P. (2003) 'You need a qualification for everything these days': the impact of work, welfare and disaffection upon the aspirations of access to higher education students, British Fournal of Sociology of Education, 24(1), 95-108. 